\title{
A perspectiva dos homens sobre os partos domiciliares planejados
}

\author{
Jacqueline Isaac Machado Brigagão* (i) \\ Roselane Gonçalves $\mathbb{B}$ \\ Universidade de São Paulo, São Paulo, SP, Brasil
}

\begin{abstract}
Resumo: Este artigo apresenta os resultados de uma pesquisa que teve por objetivo estudar a perspectiva dos homens/pais sobre o parto domiciliar e os modos como eles participaram do nascimento de seus/suas filhos/ as. Realizamos entrevistas semiestruturadas com cinco homens que participaram dos partos domiciliares e do nascimento de seus filhos. A análise discursiva possibilitou identificar que os homens prepararam-se para o parto, vivenciaram muitas expectativas e aprendizagens nesse processo, enfrentaram diversos preconceitos contra o parto domiciliar e participaram ativamente do parto e do pós-parto. Concluímos que, na perspectiva dos homens/pais, o parto domiciliar é uma experiência enriquecedora que amplia as possibilidades de participação dos homens nesse evento e o exercício da paternidade durante o planejamento e o parto.
\end{abstract}

Palavras-chave: paternidade, parto domiciliar, homens, pais.

\section{Introdução}

No Brasil, houve um processo gradativo de desvalorização da capacidade de parir das mulheres, do domicílio como local apropriado para o nascimento e do trabalho desenvolvido pelas parteiras (M. J. Spink, 2003). Atualmente, o parto e o nascimento compõem um evento basicamente hospitalar, que requer tecnologias biomédicas. A medicalização foi precedida e sustentada pelo surgimento de especialidades médicas, como a obstetrícia, a ginecologia, a embriologia e a genética, que introduziram os princípios higienistas normativos às famílias, num contínuo que se inicia nos processos reprodutivos e se estende até o momento do nascimento (Barbiani, Junges, Asquidamine, \& Sugizaki, 2014).

Um dos efeitos desse processo foi a exclusão dos homens e dos familiares da cena do parto de modo geral. Nas últimas décadas, é possível observar um conjunto de ideias, políticas públicas e movimentos sociais que buscam a retomada do protagonismo das mulheres e das famílias heteroparentais ou homoparentais no parto e no nascimento. $\mathrm{O}$ discurso profissional e os preceitos que orientam algumas políticas públicas de saúde advogam a favor da reinserção do homem no cenário do parto e do nascimento, embora haja muito o que se concretizar nesse campo das práticas em saúde (Caires \& Vargens, 2012). Por outro lado, como apontam Tornquist (2002) e Badinter (2011), nas estratégias de luta para superar o processo de medicalização e de fragmentação presentes nas práticas obstétricas, frequentemente ativistas e teóricos têm assumido posições que privilegiam as concepções naturalistas e fisiológicas, reduzindo o parto e o nascimento à dimensão biológica. Nessa corrente de

\footnotetext{
* Endereço para correspondência: jac@usp.br
}

pensamento, há uma ênfase na dimensão mamífera dos humanos no parto e uma exclusão de tudo que possa "atrapalhar" a relação fisiológica entre mãe e bebê (Odent, 1981). Essa perspectiva reforça a exclusão dos homens da cena do parto e do nascimento e os estereótipos de gênero fundados na biologia.

A concepção do parto e do nascimento como evento familiar tem sido um dos argumentos de famílias que vivem em regiões urbanas para a escolha do domicílio como local de nascimento, apesar da grande oferta de estrutura hospitalar (Feyer, Monticelli, \& Knobel, 2013). Um dos fatores que influencia a escolha do parto domiciliar planejado é a garantia da participação dos pais na cena do parto (Collaço et al., 2017; Koettker, Brüggemann, \& Dufloth, 2013). Como contraponto às discussões históricas no Brasil acerca da importância das condições de segurança e de acesso aos equipamentos de saúde, a escolha do ambiente extra-hospitalar é uma possibilidade de aproximar esse evento da família, considerando-o um acontecimento social/cultural que deve ser vivido segundo dos princípios da segurança, mas que, ao mesmo tempo, possibilite o protagonismo e o conforto das pessoas envolvidas (Castro, 2015).

As políticas públicas brasileiras reconhecem a importância da valorização da paternidade e da participação dos homens na cena do parto e do nascimento. A Política Nacional de Atenção Integral à Saúde do Homem (Portaria $n^{\circ} 1.944 / 2009$ ) incluiu a paternidade como um aspecto a ser valorizado na proposição de ações de saúde sexual e reprodutiva para os homens. A estratégia Rede Cegonha (Portaria ${ }^{\circ}$ 1.459/2011), também menciona a importância da participação dos homens no processo de gestação e parto. Quanto às pessoas presentes na cena do parto, a Lei do Acompanhante (Lei $n^{0} 11.108 / 2005$ ) assegura o direito da mulher de escolher quem poderá estar 
ao seu lado durante todo o trabalho de parto, parto e pósparto. Mas sua implementação ainda se configura como um desafio para a gestão dos serviços de saúde, sejam eles públicos ou privados, uma vez que são inúmeros os empecilhos colocados para que, de fato, a mulher usufrua desse direito. Não raro, apesar do desejo da mulher, essa possibilidade de escolha não se concretiza, pois muitos hospitais e maternidades não adequaram sua estrutura física para garantir a presença de acompanhantes do sexo masculino durante todo o processo.

Infelizmente, não existe ainda uma sistematização dos registros de número de partos domiciliares planejados na maioria dos municípios brasileiros. Porém, no município de São Paulo a notificação desse tipo de parto ocorre desde 2009, por meio do acompanhamento das declarações de nascidos vivos preenchidas e assinadas por profissionais de saúde autônomos/as cadastrados/ as na Secretaria Municipal da Saúde. Esses registros demonstram que, comparando o ano de 2018 ao de 2009, houve um crescimento de $304 \%$ no número de partos domiciliares planejados no município (Secretaria Municipal da Saúde de São Paulo, 2019).

O processo de construção da paternidade é marcado pelas histórias individuais, pelas concepções sociais e culturais de uma determinada época e pelo momento de vida no qual ocorre a paternidade. Assim, tornar-se pai envolve uma multiplicidade de sentimentos que perpassam a gravidez, o parto e o dia a dia após o nascimento do bebê. Durante todo esse período, o homem é chamado a assumir uma nova atitude nas relações intra e extrafamiliares. A expectativa é de que participe dos cuidados com a mulher/ gestante e, posteriormente, com a criança. Nessa fase de transição para a paternidade, seu papel se redefine e, na atualidade, deve superar o modelo hegemônico, segundo o qual ao homem cabia o provimento das necessidades da casa, considerando a dimensão socioeconômica, alcançando as dimensões afetivas/emocionais, relacionais e sociais. Essas vivências promovem mudanças profundas no seu modo de ver a si mesmo e o mundo. Krob, Piccinini e Silva (2009) e Moraes e Granato (2016) comentam que a gestação pode se configurar para os homens/pais como um período emocionalmente intenso, marcado por sentimentos ambivalentes de alegria, preocupação e ansiedade, que podem influenciar o modo como lidam com as situações que se apresentam nas relações de cuidado com o filho e com a mulher/mãe, o que caracteriza esse período de transição à paternidade como uma fase de expectativas e sentimentos que envolvem a tríade pai-mãe-bebê.

A gestação e a expectativa da chegada de um/a filho/a têm sido discutidas como acontecimentos transformadores que colocam os homens diante de uma multiplicidade de desafios psicológicos. Na literatura, a paternidade é apontada como um dos marcos de desenvolvimento na vida dos homens (Condon, Boyce, \& Corkindale, 2004; Souza \& Benetti, 2009; Waldvogel $\&$ Ehlert, 2016). Porém, grande parte dos estudos sobre a presença dos pais na cena do parto focaliza as percepções e sentimentos das mulheres sobre os acompanhantes, na maioria das vezes em maternidades e casas de parto (Dodou et al., 2014; Hodnett, Gates, Hofmeyr, \& Sakala, 2013; Holanda et al., 2018; Pinheiro \& Bittar, 2012). A inclusão dos homens/pais na cena do parto, pelos/ as profissionais de saúde, é apontada como sendo um modo de reconhecer que esses podem estar envolvidos no cuidado aos filhos desde os primeiros momentos de vida (Villalón, Toro, Riesco, Pinto, \& Silva, 2014).

$\mathrm{Na}$ literatura nacional e internacional do campo da saúde e da psicologia, encontramos poucas referências relativas à perspectiva dos pais sobre os partos domiciliares. De acordo com Cursino e Benincasa (2020), esse evento ainda é pouco estudado no Brasil. Em seu estudo, Jouhki, Suominen e Åstedt-Kurki (2015) buscaram compreender a experiência de parto domiciliar de 11 pais finlandeses. Eles relatam que os pais apoiaram as mulheres e compartilharam a responsabilidade ajudando-as no processo do parto em casa, o que culminou em uma experiência desafiadora carregada de fortes emoções que intensificou os vínculos familiares.

Lindgren e Erlandsson (2011) estudaram a experiência de pais suecos com o parto domiciliar e concluíram que as mulheres decidem o tipo de parto e eles aderem à essa escolha. Porém, apesar de sentirem que essa experiência fortalece o papel paterno, eles sofrem com a opção não convencional de nascimento. Sweeney e O'Connell (2015), num estudo qualitativo com pais irlandeses, constataram que os homens se beneficiam emocionalmente das experiências positivas de parto e que essa vivência pode fortalecer a relação entre o casal.

O parto e o nascimento, na perspectiva da psicologia social construcionista, são entendidos como uma experiência em que é impossível dissociar os aspectos biológicos, sociais e culturais que os constituem. Assim, no processo de produção de sentidos dessa vivência, essas três dimensões estão intimamente articuladas e aparecem nos discursos sobre o parto. Nessa abordagem, as experiências, as práticas discursivas e as interações cotidianas possibilitam a produção de sentidos, entendida aqui na acepção proposta por Spink e Medrado (2000):

O sentido é uma construção social, um empreendimento coletivo, mais precisamente interativo, por meio do qual as pessoas - na dinâmica das relações historicamente datadas e culturalmente localizadas - constroem os termos a partir dos quais compreendem e lidam com as situações e fenômenos a sua volta. (p. 41)

Assim, essa pesquisa busca construir conhecimentos sobre os sentidos produzidos por homens/ pais que participaram dos partos domiciliares de seus filhos. De acordo com P. K. Spink (2003), ao tornar algo psicologicamente relevante e útil, podemos contribuir para que saberes e conhecimentos viajem para além das fronteiras disciplinares e que outros possam associá-los a diferentes ideias e possibilidades dentro do processo de coletivização dos saberes. 


\section{Método}

Trata-se de uma pesquisa qualitativa orientada pela perspectiva construcionista, que privilegia os discursos e reconhece os aspectos microssociais e políticos envolvidos no processo de construção e análise da realidade (Rasera, Santos, \& Japur, 2016). O foco da pesquisa foram os sentidos sobre o parto domiciliar planejado e os modos de participação adotados por cinco homens que vivenciaram essa experiência. Os sentidos são produzidos de modo dialógico e dinâmico e articulam dimensões subjetivas, sociais e coletivas ao buscar descrever e explicar as diferentes vivências no cotidiano (Iñiguez, 2004; M. J. Spink, 2010).

O instrumento de pesquisa adotado foi a entrevista semiestruturada, porque possibilita uma relação dialógica marcada pela articulação e negociação de posicionamentos entre entrevistados e entrevistadores e pela produção de sentidos (Aragaki, Lima, Pereira, \& Nascimento, 2014). A entrevista realizada com os pais foi orientada por quatro eixos temáticos: o parto; a preparação para o parto domiciliar; as ações desenvolvidas pelo participante durante todo o processo; o pós-parto. As questões da entrevista circularam em torno desses temas. Como estratégia complementar, as pesquisadoras utilizaram um diário de campo para registrar as impressões pessoais e os dados do contexto acerca das entrevistas (Batista, Menegon, \& Bernardes, 2014).

O estudo foi autorizado pelo protocolo $\mathrm{n}^{\mathrm{o}}$ 746.170/2014/CAAE: 33567114.0.0000.5390, emitido pelo Comitê de Ética em Pesquisa da Escola de Artes, Ciências e Humanidades da Universidade de São Paulo (EACH/USP). Todos os participantes leram e assinaram o Termo de Consentimento Livre e Esclarecido e os dados que pudessem identificar os participantes foram suprimidos, sendo fictícios os nomes utilizados.

Foram entrevistados cinco homens, de 26 a 43 anos, que participaram do trabalho de parto e do parto domiciliar de seus filhos. Deles, quatro tinham concluído e um estava cursando o ensino superior, sendo que dois já tinham pós-graduação. Quanto ao estado civil, dois eram casados e três eram solteiros vivendo em regime de união estável, dois dos quais reconheceram a união em cartório. Os entrevistados residiam em diferentes bairros do município de São Paulo. Quanto ao regime de trabalho, três tinham vínculo empregatício fixo e dois, esporádicos. A renda familiar variou entre até três salários mínimos e mais que três salários mínimos. Três deles declararam ter outros filhos, mas apenas um participou do parto domiciliar de dois deles.

A pesquisa foi realizada no período de maio de 2015 a setembro de 2016; todas as entrevistas, realizadas nos domicílios dos participantes, foram gravadas e posteriormente transcritas. $\mathrm{O}$ recrutamento dos participantes foi possível através do contato com uma equipe de obstetrizes que realiza partos domiciliares no município de São Paulo; após identificados, eles foram contatados e todos aceitaram participar voluntariamente.
A análise discursiva privilegiou o uso de mapas dialógicos porque eles permitem dar visibilidade ao contexto, ao processo de produção de sentidos e ao modo como as pessoas descrevem o mundo em que vivem (Nascimento, Tavanti, \& Pereira, 2014). Assim, a análise teve início com a escuta atenta das entrevistas e a leitura das transcrições. A partir daí, foram identificados três temas: a preparação para o parto: expectativas e aprendizagens; o enfrentamento dos preconceitos contra o parto domiciliar; a participação no parto e no pós-parto. Esses temas constituíram as colunas do mapa dialógico, dentro das quais as transcrições de cada entrevista foram colocadas integralmente, em respeito à ordem em que o discurso foi proferido e incluídas as questões formuladas pelas entrevistadoras, o que possibilita entender o contexto dialógico de produção dos sentidos. Para cada entrevista foi construído um mapa.

\section{Resultados e discussão}

\section{A preparação para o parto: expectativas e aprendizagens}

O parto e o nascimento são eventos do cotidiano sobre os quais se constroem sentidos. Como nos centros urbanos do Brasil, há muitas décadas, o parto ocorre predominantemente nos hospitais, os participantes da pesquisa tiveram que desconstruir os modos como entendiam o evento e construir novos sentidos para o parto que ocorre no domicílio. Dois deles se referem ao fato de que antes dessa experiência não haviam pensado sobre o local do parto e justificaram que essa não é uma questão muito presente no universo masculino:

É feminino, é coisa de mulher, é coisa de mulher. Então, por exemplo, isso está endêmico. Faz parte do homem brasileiro, né? (Raimundo)

Tinha, mas na verdade eu nunca parei pra pensar assim, nesse momento, do nascimento, do parto, pra gente, vai ganhar bebêe? "Ah, é no hospital!", homem nunca nem ouve, mulher, já ouve falar em parto natural, parto em casa; homem não, homem não tem ouvido pra essas coisas. (Vitor)

Nos relatos, fica evidente que os repertórios interpretativos por eles utilizados restringem o parto a assunto de mulher e a um tipo de conversa da qual os homens não participam. Repertórios são o conjunto de termos, conceitos e figuras de linguagem que possibilitam a construção de sentidos e de versões (Potter \& Wetherell, 1987). Os repertórios sobre parto podem ser situados no que M. J. Spink (2010) denomina tempo longo, que consiste em assumir que há uma longa história de circulação de repertórios, os quais se mantêm vivos nas produções culturais e podem ser reativados nos processos de produção de sentidos. Hotimsky e Alvarenga (2002), em sua pesquisa 
sobre as escolhas das mulheres acerca dos acompanhantes no parto, afirmam que nas classes populares, a escolha de outras mulheres como acompanhantes estava associada à noção de que elas têm saberes incorporados, que podem ser encarnados devido às experiências de partos anteriores. Porém essas escolhas também aparecem associadas às noções de pudor feminino, outro aspecto que mantém os homens afastados da cena do parto.

Esses repertórios têm sido atualizados por um movimento que enfatiza a biologização do parto e do nascimento e retoma a divisão tradicional dos papéis de gênero. Trata-se de uma corrente de pensamento que entende o parto/nascimento como um evento fisiológico, no qual são primordiais a condição mamífera das mulheres e seus hormônios, o que motiva a presença dos pais na cena do parto a ser vista como um impedimento para a plena descarga hormonal (Odent, 1981). Concordamos com Badinter (2011), que toma essa leitura como reducionista, machista e promotora da volta das mulheres ao universo doméstico, afastando os homens do cuidado com filhos/ as. Além disso, é uma leitura que exclui as dimensões psicológicas, sociais e culturais do nascimento.

Antônio, um dos entrevistados, referiu-se a uma imagem do nascimento que visualizava muito antes de estar prestes a ter um filho. Ou seja, teve que desconstruir imagens e sentidos para o parto quando decidiu, com sua companheira, pelo parto domiciliar:

Eu planejava, sempre quis, com certeza, ter filhos, mas bem lá na frente. Então, eu imaginava... imaginava eu lá no hospital: ia estar do lado de uma enfermeira, ia passar mal, cair, ela ia me ajudar... aí ia acordar com tudo certinho, o nenezinho limpinho, e nem me passava pela cabeça participar, de fato, do processo, né? E é totalmente diferente: no parto domiciliar você tem que participar ativamente né?! (Antônio)

Os participantes da pesquisa tomaram conhecimento do parto domiciliar através de suas companheiras; nos cinco casos, foram as mulheres que lhes apresentaram essa possibilidade e expressaram o desejo de realizar o parto em seus domicílios. Os estudos internacionais descreveram essa mesma dinâmica em relação à escolha do local de parto, pois os autores apontam que a escolha pelo parto domiciliar foi feita pelas mulheres e os parceiros apoiaram essa decisão, respeitando os desejos delas, embora alguns tivessem reservas quanto a um parto em casa (Jouhki et al., 2015; Lindgren \& Erllandsson, 2011).

Os participantes da pesquisa buscaram informações para entender o processo, referindo-se às conversas que tiveram com suas companheiras, bem como a livros, vídeos, encontros de casais grávidos e diálogos com profissionais amigos, como afirmam Romão, Raimundo e Antonio:

Procurei assim: vi alguns vídeos, ela sempre compartilhou bastante material nesse sentido. (Romão)
Fui ler, fui estudar, fui perguntar,... eu conversei com a parteira. É a questão da informação. (Raimundo)

Ela colocava pra eu ver, né? Colocava lá no YouTube e falava: "Vem aqui assistir um vídeo de parto"... Ai começava a embrulhar o estômago, perdia a fome, ela me dava alguns livros, a gente começou a ir a encontros de gestantes também. Acho que facilitou bastante e, aí, eu fui ganhando segurança... E, a partir do momento que tudo é novidade, dá uma insegurança, né? (Antônio)

É interessante observar que ao aceitar a escolha das mulheres pelo parto domiciliar, os pais prepararam-se ativamente para o evento. Essa estratégia parece ter uma dupla função: por um lado, o parto domiciliar passa a ser um projeto comum do casal; por outro, parece amenizar as ansiedades e as incertezas relacionados a esse evento.

Três dos participantes da pesquisa se referiram explicitamente a dúvidas e temores acerca da possibilidade de acontecimentos imprevistos com a saúde da mulher e do bebê, com os quais eles não conseguiram lidar num ambiente extra-hospitalar:

O meu medo era de acontecer alguma coisa com elas e a gente não ter preparo aqui. Esse era meu medo! Porque era essa a minha preocupação: "Se acontece alguma coisa, o que eu faço?”. (Antônio)

Ah, preocupação acho que ela sempre vai... não, não sei, mistura um pouco as coisas, ansiedade, um pouco de medo. (Romão)

Minha pergunta pra ela foi: e se der algum problema? (Raimundo).

Para eles, foi fundamental conversar com a equipe e com as companheiras para se certificarem de que dispunham de todo o equipamento necessário para lidar com emergências, além de um hospital de referência para uma possível transferência:

Tinha, um plano: a gente ia pro São Camilo, né? É aqui pertinho... Tinha uma médica. Se acontecesse alguma coisa, a gente ia pro hospital com essa médica. (Antônio)

Se der algum problema... [a obstetriz] falou: "Tem um hospital que você indica assim, assim, assim". Tem uma dinâmica. (Raimundo)

Então eu não fiquei tão preocupado nesse sentido de acontecer alguma coisa, algum problema, a gente teve o suporte também necessário [tinha as obstetrizes], então a gente tinha o suporte, tinha os materiais que eram necessários para o momento, estava tranquilo. (Romão) 
Além da garantia de uma equipe hospitalar de referência e dos equipamentos necessários para atender uma eventual emergência, os vínculos de confiança e a orientação oferecida pela equipe de obstetrizes foram fundamentais para diminuir os temores em relação ao parto no ambiente extra-hospitalar. Estudos têm demonstrado que a orientação da equipe de saúde para o acompanhante é fundamental para que ele amplie suas formas de participação no parto (Motta \& Crepaldi, 2005; Oliveira \& Silva, 2012; Souza \& Benetti, 2009).

Na pesquisa realizada por Jouhki et al. (2015) sobre os partos domiciliares, os pais verbalizaram que sofreram ao pensar na possibilidade de a esposa ou o bebê morrerem devido à ampliação dos riscos de partos realizados fora do contexto hospitalar. Os pais participantes da nossa pesquisa não expressaram claramente esse temor e falaram somente de modo geral sobre a possibilidade de acontecer algo nesse sentido. Isso ocorreu provavelmente porque em nossa cultura, a morte ainda é vista como um tabu sobre o qual é difícil falar abertamente, mesmo quando é somente uma possibilidade.

Para os participantes da pesquisa, o parto domiciliar foi uma experiência gratificante e de muitas aprendizagens. Eles afirmam que inicialmente foi uma escolha de suas companheiras e que elas lhes apresentaram essa possibilidade, iniciando, de certo modo, um processo de socialização dos pais sobre o parto domiciliar, por meio da apresentação de novos repertórios sobre o parto e o nascimento. Ao longo da gestação, a escolha passou a ser também deles, que participaram ativamente no planejamento do parto, em preparação para o evento.

Quanto à participação/envolvimento do homem/ pai no processo de parto e nascimento, alguns autores comentam que a hospitalização do parto e sua transformação em um evento médico podem dificultar o envolvimento afetivo dos pais e sua participação no parto (Piccinini, Silva, Gonçalves, Lopes, \& Tudge, 2004). Por outro lado, outras pesquisas, realizadas em contextos institucionais, acerca da presença dos pais na sala de parto apontaram que eles se instruíram durante a gestação, buscando informações na internet e assistindo a vídeos que pudessem preparálos para o momento do nascimento e para apoiarem as mulheres (Oliveira \& Silva, 2012). Isso vem ao encontro das afirmações de Antunes, Pereira, Vieira e Lima (2014), segundo os quais, apesar de os pais perceberem a vivência do parto como um momento de bastante sofrimento, tensão, emoção e medo, tal evento pode propiciar uma oportunidade de lidar com esses sentimentos e emoções, facilitar a aproximação das mulheres e ressignificar os papéis tradicionalmente atribuídos à paternidade.

No entanto, Teixeira, Souza de Sá e Arrais (2009) apontam que além da necessidade de fomentar o envolvimento dos homens/pais no cenário do parto, é fundamental educar as/os profissionais de saúde acerca da importância da presença do acompanhante de livre escolha da mulher durante o trabalho de parto, parto e pós-parto, pois ainda há muitas resistências à presença do acompanhante em todo o período de internação no cenário hospitalar.

\section{Enfrentando os preconceitos contra o parto domiciliar}

O parto domiciliar planejado ainda é pouco conhecido no Brasil, e os casais que optam por ele frequentemente sofrem discriminações e críticas. $\mathrm{Na}$ pesquisa, todos os participantes disseram ter se defrontado com o desconhecimento acerca da possibilidade de realizar um parto no domicílio. Isso provavelmente ocorreu porque, em suas famílias, os entrevistados passaram a constituir a primeira geração que escolheu o domicílio como local para o nascimento. É interessante observar que os familiares mais próximos e íntimos expressaram claramente que entendiam o parto como um evento arriscado, que necessita de hospitalização e muitas tecnologias, e, portanto, é preocupante. Nesse contexto, uma das atitudes que eles assumiram foi parar de tentar explicar e negociar com as pessoas que eram contrárias ao parto domiciliar:

Ela [a avó paterna] falava que era loucura: "deixa disso, isso é coisa de gente antiga”. Hoje em dia você tem que ir em hospital, você tem tecnologia. (Vitor)

Minha mãe, no princípio a gente falou e ela: "Nossa,
não, vocês são malucos, é muito arriscado!".
Meu irmão é todo certinho, sabe? "Cara, você está
maluco, pelo amor de Deus, não faz isso!". Tem
um amigo bem próximo no trabalho, o pai dele era
médico, e eu comentei com ele. Aí, no dia seguinte,
ele me chamou e falou: "Antonio, meu pai pediu pra
eu te avisar pra não fazer nenhuma loucura". E toda
semana ele abordava o assunto: "Você não vai fazer,
né? Meu pai falou que é muito perigoso". E continuou,
até que eu falei: "Não vou fazer!". (Antônio)

Os preconceitos, medos e as resistências que os pais encontraram entre os amigos e familiares, quando falavam sobre a escolha pelo parto domiciliar, estão associados à noção amplamente disseminada de que os partos requerem hospitalização e medicalização. Castro (2015), em sua pesquisa com mulheres que optaram por partos domiciliares, relata que elas também sofreram muitas resistências, sendo chamadas de "loucas". No estudo de Lindgren e Erlandsson (2011), os pais relataram que tiveram que lidar com seus próprios sentimentos relacionados ao fato de serem diferentes em comparação com as formas convencionais de se tornar pai. A pesquisa de Jouhki et al. (2015) também apontou que os pais ficaram profundamente magoados com as pessoas que julgaram suas escolhas e condenaram o parto domiciliar.

\section{Participando do parto e do pós-parto}

Para que o parto aconteça em casa, é necessário um amplo planejamento, que inclui ajustes no espaço físico, aquisição de alguns materiais e utensílios e até 
a adoção de algumas providências específicas. Então, para alguns, esse processo começou, no planejamento, com a compra de materiais e testes de funcionamento de alguns deles para assegurar que tudo estava funcionando:

Foi até uma diversão, a gente encontrar uma piscina e preparar o ambiente. Não só a piscina, é tentar deixar o ambiente mais tranquilo. (Romão)

Uma semana antes,... montar banheira, ligar. Até colocar a mangueira, a água... A gente fez o teste,... pode ficar ali. Então a gente preparou todo o ambiente pra chegar na hora e não ficar aquele: o que é que faz com isso aqui? (Raimundo)

Os pais relataram ter participado do processo desde o início, alguns deles assumindo o papel de anfitrião, provedor e cuidador, focados em organizar a casa, receber a equipe e cuidar para que tudo acontecesse como planejado:

Eu fiquei dividido, um pouco eu cuidava [dela], um pouco eu conversava, fazia um suco e tal, sabia que o processo ia ser demorado. (Vitor)

Então, tudo o que era necessário fazer enquanto função prática, eu fui fazendo aleatoriamente ou, às vezes, até a pedidos [das obstetrizes]... Então, num primeiro momento, eu subi e fui encher a piscina. Isso era duas horas da manhã. E, assim, uma outra energia que eu sentia também era a energia de guardião, de ser o dono da casa, recebendo as pessoas pra que minha filha nascesse, sabendo que minha mulher não tinha condições nenhuma de receber ninguém. E eu estava com essa sensação de guardião mesmo, de estar disponivel a todos. (Inácio)

Alguns pais participaram intensamente do processo, numa relação íntima e corporal com as companheiras, inclusive no momento do parto:

Dentro do possivel tentava acalmá-la, fazendo respiração para ela tentar acompanhar a respiração, algum tipo de carinho, gesto. (Romão)

$\dot{E}$, ela sentou entre as minhas pernas e aí a [parteira] ficou de prontidão, né? Esperando e, aí, ele nasceu. Quando ele nasceu eu senti ele escorregando nas pernas, senti o calor interno da mulher ejá vi o bebê na mão [da parteira]. (Vitor)

Eu lembro que eu apertava a perna [dela] e pensava comigo: "Vai nascer, vem". E, quando a bolsa estourou, segundos antes de nascer, eu falei: "Olha, tá saindo, tá saindo", e eu apertando [a perna dela]. Tanto é que nas fotos parece que eu tô machucando a perna dela. (Inácio)
Todos relataram que vivenciaram emoções intensas ao longo do processo, sendo que dois pais disseram ter chorado ao final do parto. Todos cortaram o cordão umbilical, uma experiência muito marcante para alguns deles:

E ela pegou [a bebê] e aí veio o choro, o grito: "Nasceu, amor, nasceu!". E choro pra lá e grito pra lá, enfim. (Inácio)

Eu despenquei... Isso não estava combinado, né? A obstetriz olhou pra mim e falou: "Você quer [cortar o cordão]?” E eu falei: “Quero, quero!” Muito legal... Me senti bem e me senti assim, era uma coisa que eu deveria ter planejado fazer, e, se não fosse [ela] falar na hora... a emoção era tão grande que ia passar batido. E é um negócio que me marcou. (Antônio)

A possibilidade de participar ativamente do parto foi importante para os participantes, que sentiram estar apoiando, trocando afeto com suas companheiras e seus/ suas filhos/as. Todos parecem ter superado as noções tradicionais de que o parto é um evento feminino e passaram a vê-lo como um acontecimento enriquecedor afetivamente para os homens, um dos modos de exercer a paternidade. A pesquisa de Jouhki et al. (2015) encontrou resultados similares aos nossos: os pais relataram ter participado do parto domiciliar física e emocionalmente. Eles se dedicaram a apoiar as mulheres durante o trabalho de parto e pósparto, o que significava estar presente e a postos para atender às demandas delas. Assumiram também o papel de donos da casa, além da responsabilidade pela organização do ambiente, como a preparação da piscina e, em alguns casos, até a realização de pequenas reformas. Além disso, eles relataram ter sido uma experiência emocionalmente muito forte e alguns deles, apesar de ter se passado muito tempo, ainda se emocionavam ao falar do parto.

Todos se referiram ao parto domiciliar como uma experiência intensa afetiva e fisicamente, ao final da qual estavam exaustos. Alguns dormiram quase imediatamente; outros, apesar do cansaço, não conseguiram descansar:

Eu estava cansado. A noite toda, né? Mas depois passou também. Fiquei o dia todo acordado, não dormi. (Vitor)

Um alivio, né? Uma sensação de alívio. Estava tudo bem, ela tinha nascido, aí eu consegui, desmaiei, desmaiei literalmente. Deitei na cama com ela. (Antônio)

É lindo, mas é intenso. Queria [dormir], mas não conseguia, a gente ficou 24 [horas] de parto, mais o outro dia, acho que a gente ficou umas 50 horas virado. Porque eu estava na adrenalina. (Romão)

Apesar de cada um, a seu modo, ter participado do parto, alguns afirmaram que gostariam de ter se 
preparado melhor, em busca de um envolvimento ainda mais ativo. É o que planejam, caso tenham mais filhos:

Eu não imagino [o próximo parto] no hospital, mas acho que eu teria que me preparar ainda,... e agora acho que eu teria mais: "Oh, a gente vai fazer desse jeito". Me colocaria mais, sabe? Acho que eu fui muito passivo nesse. (Antônio)

Eu não estava esperando esse processo, esse trabalho de força que é a parte da contração mais forte, tão longo. Eu achei que seria menor. Então, eu não estava preparado para isso, sinceramente... Com relação ao parto normal, eu preciso me preparar um pouco mais... Não sei, tem momentos que eu achei superlindo, e realmente é. Mas eu acho que você tem que estar preparado, porque é muita emoção ali e próxima, $e$ você é um participante da cena. Então você tem que estar preparado. (Romão)

O domicílio possibilita a presença de outras pessoas durante todo o processo, mas essa foi uma escolha que variou muito entre os casais. Romão e sua companheira optaram por não ter ninguém além da equipe de obstetrizes. No caso de Raimundo, o casal escolheu uma amiga da mulher para acompanhar o processo. $\mathrm{Na}$ casa de Antônio estavam a mãe e uma amiga de sua companheira. No caso de Vitor, no primeiro parto estava presente uma irmã de sua companheira e no segundo, somente a equipe de obstetrizes. Inácio e a companheira contaram com a ajuda da mãe e do padrasto dela, chamados para dar apoio à filha mais velha do casal. A relação com a família e os amigos está permeada por todas as conversas e negociações anteriores ao parto domiciliar, mas todos disseram ter telefonado para as pessoas mais próximas logo após o nascimento.

É interessante observar que os pais vivenciam, no pós-parto, muitas emoções e buscam elaborar e consolidar os sentidos produzidos para todo o processo do parto, ao mesmo tempo em que já estão envolvidos numa outra tarefa muito intensa, que é cuidar de um recém-nascido:

Foi uma coisa muito bonita, tanto é que eu chego na varanda, que foi onde ela nasceu, vira e mexe vêm flashes da hora, do segundo que ela nasceu. Não só de quando ela nasceu, mas de todo o movimento que aconteceu naquela noite, por ter essa observação de que era o universo pulsando pra que ela viesse ao mundo E foi muito bonito, realmente foi a experiência mais bonita e mais maravilhosa da minha vida, real, crua, uma coisa verdadeira. O pai tem que estar presente desde o primeiro momento, e por toda a vida ele tem que estar ali do lado. (Inácio)
É interessante observar que os participantes da pesquisa se referem ao parto como um momento de vivências afetivas intensas e que entendem que, ao participar do processo de planejamento e de parto, já iniciaram o exercício da paternidade.

\section{Considerações finais}

A pesquisa permitiu reconhecer que, na contemporaneidade, há homens que desejam vivenciar as emoções e os afetos da parentalidade durante todo o trabalho de parto e que, para eles, participar ativamente desse processo é uma experiência enriquecedora.

Inicialmente, os participantes não sabiam muito sobre o parto domiciliar, mas, ao longo da gestação e do processo de planejamento do parto, aprenderam e produziram sentidos que lhes permitiram participar ativamente. Assim, podemos dizer que os homens/pais participaram de diversos modos, preparando o ambiente $\mathrm{e}$ garantindo todas as condições materiais para que o parto ocorresse. Participaram afetiva e fisicamente, dizendo palavras encorajadoras, abraçando, massageando, dando suporte corporal para as mulheres durante as contrações e no parto, cortando o cordão umbilical dos/as bebês. Participaram também no pós-parto reorganizando a casa, deitando-se ao lado das companheiras e dos/as bebês.

$\mathrm{O}$ parto domiciliar planejado configura-se como uma oportunidade para que os pais participem ativamente do processo de nascimento. Especificamente nesse caso, três fatores parecem ter contribuído para isso: o primeiro foi a disponibilidade dos casais para realizarem juntos o parto domiciliar e compartilharem informações desde o princípio; o segundo, o vínculo com os/as profissionais que acompanharam o parto e nascimento. Esse vínculo foi construído ao longo do prénatal, quando eles/as tiveram a preocupação de orientar os casais sobre os padrões de segurança estabelecidos para os partos de baixo risco, explicar e esclarecer todas as dúvidas dos pais, bem como desenvolver ações de cuidado e suporte emocional à parturiente, ao companheiro/a e às/aos bebês. O terceiro fator é que o ambiente domiciliar proporciona maior controle da situação por parte das mulheres e dos homens, já que elas têm liberdade de ir e vir durante o trabalho de parto, escolhendo o local e a posição, bem como o que comer e beber. Além disso, o casal decide quem serão as pessoas presentes durante o processo.

Portanto acreditamos que é importante avançar em pesquisas sobre os partos domiciliares planejados no campo da psicologia a fim de ampliar a discussão sobre as múltiplas dimensões desse evento e as repercussões psicossociais da participação dos homens/pais neste momento. 


\section{The male perspective on planned home birth}

Abstract: This article reports the results of a research on how fathers perceive and participate in homebirths. For that, five men who participated in the homebirth of their children underwent a semi-structured interview, whose content was analyzed by means of discourse analysis. The results indicate that, despite the prejudices against homebirth faced by these men, they actively participated in childbirth and postpartum, preparing themselves and experiencing different concerns and learning throughout this process. From the male perspective, homebirth is an enriching experience that increase men's participation and widen the exercise of paternity during the whole process.

Keywords: paternity, home birth, men, father.

\section{Le point de vue des hommes sur l'accouchement assisté à domicile}

Résumé : Cet article présent les résultats d'une recherche qui a eu pour but d'étudier le point de vue des hommes/parents sur l'accouchement assisté à domicile et la manière dont ils ont y participé. Nous avons mené des interviews semi-structurés avec cinq hommes qui ont participé à des accouchements assistés à domicile. L'analyse discursive a permis d'identifier que les hommes se sont préparés à l'accouchement, ont vécu de nombreuses attentes et ont appris dans ce processus, ont fait face à divers préjugés contre l'accouchement à domicile et ont participé activement à l'accouchement et au post-partum. On conclut que pour les hommes/parents, l'accouchement assisté à domicile est une expérience enrichissante qui élargit les possibilités de participation des hommes à cet événement et l'exercice de la paternité pendant la planification et l'accouchement.

Mots-clés : paternité, accouchement assisté à domicile, hommes, parents.

\section{La perspectiva de los hombres sobre partos domiciliarios planificados}

Resumen: En este artículo presentamos los resultados de una investigación que tuvo por objetivo estudiar la perspectiva de los hombres/padres sobre el parto domiciliar y los modos en que ellos participaron en el nacimiento de sus hijos/as. Realizamos entrevistas semiestructuradas con cinco hombres que participaron en los partos domiciliarios y el nacimiento de sus hijos/ as. El análisis discursivo posibilitó identificar que vivenciaron muchas expectativas y aprendizajes en ese proceso; enfrentaron diversos prejuicios contra el parto domiciliar y participaron activamente en el parto y en el posparto. Concluimos que en la perspectiva de los hombres/padres el parto domiciliar es una experiencia enriquecedora que amplía las posibilidades de participación de ellos en ese evento y el ejercicio de la paternidad durante todo el proceso de planificación y del parto.

Palabras clave: paternidad, parto domiciliar, hombres, padres.

\section{Referências}

Antunes, J. T., Pereira, L. B., Vieira, M. A., \& Lima, C. A. (2014). Presença paterna na sala de parto: expectativas, sentimentos e significados durante o nascimento. Revista de Enfermagem da UFSM, 4(3), 536-545. doi: 10.5902/2179769212515

Aragaki, S., Lima, M. L., Pereira, C., \& Nascimento, V. (2014). Entrevistas: negociando sentidos e coproduzindo versões de realidade. In M. J. Spink, J. Brigagão, V. Nascimento, \& M. Cordeiro (Orgs.), A produção de informação na pesquisa social: compartilhando ferramentas (pp. 57-72). Rio de Janeiro, RJ: Centro Eldelstein de Pesquisas Sociais.

Badinter, E. (2011). O conflito: a mulher e a mãe. Rio de Janeiro, RJ: Record.

Barbiani, R., Junges, J. R., Asquidamine, F., \& Sugizaki, E. (2014). Metamorfoses da medicalização e seus impactos na família brasileira. Physis: Revista de Saúde Coletiva, 24(2), 567-587. doi: 10.1590/S0103-73312014000200013

Batista, N., Menegon, V., \& Bernardes, J. (2014). Conversas no cotidiano: um dedo de prosa na pesquisa. In M. J. Spink, J. Brigagão, V. Nascimento, \& M. Cordeiro (Orgs.), A produção de informação na pesquisa social: compartilhando ferramentas (pp. 97-122). Rio de Janeiro, RJ: Centro Eldelstein de Pesquisas Sociais.

Caires, T. L. G., \& Vargens, O. M. C. (2012). A exclusão do pai da sala de parto: uma discussão de género e poder. Revista de Enfermagem Referência, 3(7), 159-168. doi: 10.12707/RIII1163

Castro, C. M. (2015). Os sentidos do parto domiciliar planejado para mulheres do município de São Paulo, São Paulo. Cadernos Saúde Coletiva, 23(1), 69-75. doi: 10.1590/1414-462X201500010012 
Collaço, V. S., Santos, E. K. A., Souza, K. V., Alves, H. V., Zampieri, M. F., \& Gregório, V. R. P. (2017). O significado atribuído pelo casal ao parto domiciliar planejado, assistido pelas enfermeiras obstétricas da equipe Hanami. Texto \& Contexto - Enfermagem, 26(2), pp. 1-9. doi: 10.1590/0104-07072017006030015

Condon, J. T., Boyce, P., \& Corkindale, C. J. (2004). The firsttime fathers study: a prospective study of the mental health and wellbeing of men during the transition to parenthood. Australian \& New Zealand Journal of Psychiatry, 38(1-2), 56-64. doi: 10.1177/000486740403800102

Cursino, T. P., \& Benincasa, M. (2020). Parto domiciliar planejado no Brasil: uma revisão sistemática nacional. Ciência \& Saúde Coletiva, 25(4), 1433-1444. doi: 10.1590/1413-81232020254.13582018

Dodou, H. D., Rodrigues, D. P., Guerreiro, E. M., Guedes, M. V. C., Lago, P. N., \& Mesquita, N. S. (2014). A contribuição do acompanhante para a humanização do parto e nascimento: percepções de puérperas. Escola Anna Nery, 18(2), 262-269. doi: 10.5935/1414-8145.20140038

Feyer, I. S. S., Monticelli, M., \& Knobel, R. (2013). Perfil de casais que optam pelo parto domiciliar assistido por enfermeiras obstétricas. Escola Anna Nery, 17(2), 298305. doi: 10.1590/S1414-81452013000200014

Hodnett, E. D., Gates, S., Hofmeyr, G. J., \& Sakala, C. (2013). Continuous support for women during childbirth (Review) [Resenha do artigo Continuous support for women during childbirth, de E. D. Hodnett, S. Gates, G. Justus Hofmeyr, C. Sakala]. Cochrane Database Systematic Reviews, 7. Recuperado de https://bit.ly/3jrIzan

Holanda, S. M., Castro, R. C. M. B., Aquin, P. S., Pinheiro, A. K. B., Lopes, L. G., \& Martins, E. S. (2018). Influência da participação do companheiro no prénatal: satisfação de primíparas quanto ao apoio no parto. Texto \& Contexto - Enfermagem, 27(2), e3800016. doi: 10.1590/0104-070720180003800016

Hotimsky, S. N., \& Alvarenga, A. T. (2002). A definição do acompanhante no parto: uma questão ideológica? Revista Estudos Feministas, 10(2), 461-481. doi: 10.1590/ S0104-026X2002000200015

Iñiguez, L. (2004). Manual de análise do discurso em ciências sociais. Petrópolis, RJ: Vozes.

Jouhki, M. R., Suominen, T., \& Åstedt-Kurki P. (2015). Supporting and sharing-home birth: fathers' perspective. American Journal of Men's Health, 9(5), 421-429. doi: 10.1177/1557988314549413

Koettker, J. G., Brüggemann, O. M., \& Dufloth, R. M. (2013). Partos domiciliares planejados assistidos por enfermeiras obstétricas: transferências maternas e neonatais. Revista da Escola de Enfermagem da USP, 47(1), 15-21. doi: 10.1590/S0080-62342013000100002

Krob, A. D., Piccinini, C. A., \& Silva, M. R. (2009). A transição para a paternidade: da gestação ao segundo mês de vida do bebê. Psicologia USP, 20(2), 269-291. doi: 10.1590/S0103-65642009000200008

Lei $\mathrm{n}^{o} 11.108$, de 7 de abril de 2005. (2005, 8 de abril). Altera a Lei $\mathrm{n}^{\circ} 8.080$, de 19 de setembro de 1990, para garantir às parturientes o direito à presença de acompanhante durante o trabalho de parto, parto e pós-parto imediato, no âmbito do Sistema Único de Saúde. Diário Oficial da União. Recuperado de https://bit.ly/2Vz3pMy

Lindgren, H., \& Erlandsson, K. (2011). She leads, he follows: fathers' experiences of a planned home birth. A Swedish interview study. Sex Reprod Healthc, 2(2), 65-70. doi: 10.1016/j.srhc.2010.12.002

Moraes, C. J., \& Granato, T. M. M. (2016). Tornando-se pai: uma revisão integrativa da literatura sobre a transição para a paternidade. Psicologia em Estudo, 21(4), 557567. doi: 10.4025/psicolestud.v21i4.29871

Motta, C. C. L., \& Crepaldi, M. A. (2005). O pai no parto e apoio emocional: a perspectiva da parturiente. Paidéia, 15(30), 105-118. doi: 10.1590/S0103-863X2005000100012

Nascimento, V., Tavanti, R., \& Pereira, C. (2014). O uso de mapas dialógicos como recurso analítico em pesquisas cientificas. In M. J. Spink, J. Brigagão, V. Nascimento, \& M. Cordeiro (Orgs.), A produção de informação na pesquisa social: compartilhando ferramentas (pp. 247-272). Rio de Janeiro, RJ: Centro Eldelstein de Pesquisas Sociais.

Odent, M. (1981). Gênese do homem ecológico: mudar a vida, mudar o nascimento: o instinto reencontrado. São Paulo, SP: Tao.

Oliveira, A. G., \& Silva, R. R. (2012). Parto também é assunto de homem: uma pesquisa clínico-qualitativa sobre a percepção dos pais acerca de suas reações psicológicas durante o parto. Interação em Psicologia, 16(1) 113-123. doi: 10.5380/psi.v16i1.22970

Piccinini, C. A., Silva, M. R., Gonçalves, T. R., Lopes, R. S., \& Tudge, J. (2004). O envolvimento paterno durante a gestação. Psicologia: Reflexão e Crítica, 17(3), 303314. doi: 10.1590/S0102-79722004000300003

Pinheiro, B. C., \& Bittar, C. M. L. (2012). Percepções, expectativas e conhecimentos sobre o parto normal: relatos de experiência de parturientes e dos profissionais de saúde. Aletheia, 37, 212-227. doi: 10.29327/226091

Portaria $\mathrm{n}^{\mathrm{o}}$ 1.459, de 24 de junho de 2011. (2011, 27 de junho). Institui, no âmbito do Sistema Único de Saúde, a Rede Cegonha. Diário Oficial da União. Recuperado de https://bit.ly/3yuTSot

Portaria $\mathrm{n}^{\mathrm{o}}$ 1.944, de 27 de agosto de 2009. (2009, 27 de agosto). Institui no âmbito do Sistema Único de Saúde (SUS) a Política Nacional de Atenção Integral à Saúde do Homem. Brasília, DF. Recuperado de https://bit.ly/3juepTJ

Potter, J., \& Wetherell, M. (1987). Discourse and social psychology. London: Sage Publications.

Rasera, E. F., Santos L. A., \& Japur, M. (2016). Redescrições de si e o processo grupal: os lugares da mulher vivendo com HIV/AIDS. Athenea, 16(3), 423-445. doi: 10.5565/ rev/athenea.2014

Secretaria Municipal da Saúde de São Paulo. (2019). Nascer no município de São Paulo: um retrato dos partos não hospitalares. Boletim CEinfo Análise, 16(17), 1-23.

Souza, C. L. C., \& Benetti, S. P. C. (2009). Paternidade contemporânea: levantamento da produção acadêmica 
no período de 2000 a 2007. Paidéia, 19(42), 97-106. doi: 10.1590/S0103-863X2009000100012

Spink, M. J. (2003). História da obstetrícia moderna. In M. J. Spink (Org.), Psicologia social e saúde: práticas, saberes e sentidos (pp. 169-193). Petrópolis, RJ: Vozes.

Spink, M. J. (2010). Linguagem e produção de sentidos no cotidiano. Rio de Janeiro, RJ: Centro Edelstein de Pesquisas Sociais.

Spink, M. J. P., \& Medrado, B. (2000). Produção de sentido no cotidiano: uma abordagem teórico-metodológica para a análise das práticas discursivas. In M. J. P. Spink (Org.), Práticas discursivas e produção de sentido no cotidiano: aproximações metodológicas (pp. 41-61). São Paulo, SP: Cortez.

Spink, P. K. (2003). Pesquisa de campo em psicologia social: uma perspectiva pós-construcionista. Psicologia \& Sociedade, 15(2), 18-42. doi: 10.1590/S010271822003000200003

Sweeney, S., \& O'Connell, R. (2015). Puts the magic back into life: Fathers' experience of planned home birth. Women Birth, 28(2), 148-153. doi: 10.1016/j. wombi.2014.12.001
Teixeira, L. P., Souza de Sá, R., \& Arrais, A. R. (2009). Percepções da equipe obstétrica sobre a presença do pai durante parto e sobre a lei do acompanhante. Revista Eletrônica de Psicologia e Políticas Públicas, 1(1), 127-145.

Tornquist, C. S. (2002). Armadilhas da nova era: natureza e maternidade no ideário da humanização do parto. Estudos Feministas, 10(2), 483-492. doi: 10.1590/ S0104-026X2002000200016

Villalón, U. H., Toro, R., Riesco, I., Pinto, M., \& Silva, C. (2014). Participación paterna en la experiencia del parto. Revista Chilena de Pediatría, 85(5), 554-560. doi: 10.4067/S0370-41062014000500005

Waldvogel, P., \& Ehlert, U. (2016). Contemporary fatherhood and its consequences for paternal psychological wellbeing: a cross-sectional study of fathers in Central Europe. Frontiers in Public Health, 4(199), 1-14. doi: 10.3389/fpubh.2016.00199

Recebido: 11/10/2017

Revisado: 11/09/2020

Aprovado: 12/05/2021 